\title{
ADUBAÇÃO POTÁSSICA EM HÍBRIDOS DE SORGO FORRAGEIRO CULTIVADOS EM SISTEMAS DE MANEJO DO SOLO NA AMAZÔNIA ORIENTAL ${ }^{1}$
}

\author{
JESSIVALDO RODRIGUES GALVÃO ${ }^{2 *}$, ANTONIO RODRIGUES FERNANDES ${ }^{3}$, VICENTE FILHO ALVES SIVA ${ }^{4}$, \\ DANIEL PEREIRA PINHEIRO ${ }^{5}$, NILVAN CARVALHO MELO ${ }^{6}$
}

\begin{abstract}
RESUMO - O sorgo é cultivado em áreas e situações ambientais muito secas e/ou muito quentes, onde a produtividade de outros cereais é antieconômica. O objetivo foi avaliar a produção de três híbridos de sorgo em razão de doses de potássio e de sistemas de manejo, cultivados em Latossolo Amarelo da região da Amazônia Oriental. O delineamento experimental foi em blocos casualizados, arranjados em esquema fatorial $4 \times 3 \times 2$, com quatro repetições. Os fatores foram: quatro doses de potássio $\left(50,100,200\right.$ e $\left.300 \mathrm{~kg} \mathrm{ha}^{-1}\right)$ na forma de $\mathrm{KCl}$; três híbridos de sorgo (Qualimax, Volumax e AG 2005-E); e dois sistemas de manejo (plantio direto e convencional). Os híbridos volumax e qualimax apresentaram maior produção de matéria seca da parte aérea do sorgo no sistema de plantio direto. Os teores de N, P, K, Ca e Mg no tecido foliar do sorgo foram maiores no plantio direto. As doses de potássio resultaram em maior produção de MSPA no plantio direto, com redução de $40 \%$ do adubo potássico aplicado em relação ao plantio convencional.
\end{abstract}

Palavras-Chave: Sorghum bicolor L. Plantio direto. Silagem.

\section{POTASSIUM FERTILIZATION IN HYBRID FORAGE Sorghum GROWN IN DIFFERENT SOIL MANAGEMENT SYSTEMS IN EASTERN AMAZON}

\begin{abstract}
Sorghum is grown in areas and environmental situations very dry and/or too hot, where productivity of other cereals is uneconomical. Aiming to evaluate the production of three sorghum hybrids, because of potassium and management systems, grown in Oxisol with low productive capacity, an experiment was conducted in the field, in the area of the Federal Rural University of Amazonia/UFRA, Belém campus The experimental design was randomized in blocks, arranged in a factorial $4 \times 3 \times 2$ with four replications. The factors were: four doses of potassium $\left(50,100,200\right.$ and $300 \mathrm{~kg} \mathrm{ha}^{-1}$ ) as $\mathrm{KCl}$, three sorghum hybrids (Qualimax, Volumax and AG 2005-E) and two tillage systems (no-till and conventional). The tillage produced a higher shoot dry weight of sorghum, and the hybrid and Volumax and Qualimax had incomes above the AG2005-E. The contents of the elements $\mathrm{N}, \mathrm{P}, \mathrm{K}, \mathrm{Ca}$ and $\mathrm{Mg}$ in the leaves of sorghum grown with tillage were higher than those found in conventional tillage. Doses of potassium resulted in greater increase in MSPA tillage using $40 \%$ less potash fertilizer with the conventional system.
\end{abstract}

Keywords: Sorghum bicolor L.. Nutrients tillage. Silage.

\footnotetext{
*Autor para correspondência

${ }^{1}$ Recebido para publicação em 14/08/2014; aceito em 13/05/2015.

Artigo extraído da Tese do primeiro autor.

${ }^{2}$ Doutor em Ciências Agrárias, Instituto de Ciências Agrárias (ICA), Universidade Federal Rural da Amazônia (UFRA), 66.077-901, Belém (PA); jessivaldogalvão@ufra.edu.br.

${ }^{3}$ Doutor, Professor Associado, Instituto de Ciências Agrárias (ICA), UFRA, 66.077-901, Belém (PA).

${ }^{4}$ Doutor, Professor Assistente - UFRA/Campus de Parauapebas, 68.515-970, Parauapebas (PA).

${ }^{5}$ Mestre, Professor Assistente - UFRA/Campus de Capanema e Doutorando em Ciência do Solo, Depto. de Solos e Adubos, UNESP, 14884-900, Jaboticabal (SP).

${ }^{6}$ Doutorando em Ciência do Solo, Depto. de Solos e Adubos, UNESP, 14884-900, Jaboticabal (SP).
} 


\section{INTRODUÇÃO}

No Brasil, o sorgo (Sorghum bicolor L.) vem aumentado consideravelmente sua produção nos últimos tempos. Muito desse incremento se deve ao aumento da área plantada, utilização de novas tecnologias de cultivo e uso de genótipos mais produtivos e adaptados às condições edafoclimáticas de plantio (TERRA et al., 2010).

$\mathrm{O}$ cereal vem ganhando destaque no mercado nacional devido a expansão do seu processo produtivo e o fortalecimento de sua posição de cultura alternativa ao milho na produção de silagens e grãos. Outro fato que tem contribuído para alavancar a produção da cultura é que o sorgo pode ser cultivado em áreas e situações ambientais muito secas e/ou muito quentes, onde a produtividade de outros cereais é antieconômica. Além disso, apresenta menor exigência em nutrientes e fertilidade de solo quando comparado ao milho (RIBAS et al., 2007).

O sorgo forrageiro é uma das plantas mais indicadas para a produção de silagem por apresentar elevado rendimento e características que favorecem o perfil de fermentação desejável, assim como adequados teores de matéria seca e de substratos fermentescíveis, além de sua versatilidade e eficiência, tanto do ponto de vista fotossintético como em velocidade de maturação, podendo ser também utilizado como alimento humano e animal (FERNANDES et al., 2009). Ele também pode ser utilizado para a produção de silagens e como planta de cobertura. (SILVA et al., 2012).

Os solos da Amazônia são representados em sua maioria por Latossolos e Argissolos de acidez elevada e baixa fertilidade e baixo teor de $\mathrm{P}, \mathrm{Ca}, \mathrm{Mg}$ e $\mathrm{K}$, porém apresenta elevados teores de $\mathrm{Al}$ e $\mathrm{Fe}$, além de serem facilmente alterados quimicamente com a substituição da floresta primária por cultivos intensivos. A utilização de técnicas convencionais de exploração agrícola nesses solos, invariavelmente, tem resultado em degradação e consequentes abandonos das áreas (DE MELLO et al., 2009). Entre os nutrientes extraídos pelas culturas destinadas à produção de silagem o potássio $(\mathrm{K})$ merece atenção especial pelo fato de que, quantitativamente, a sua extração e exportação é grande e o seu teor em solos altamente intemperizados são geralmente baixos. Dentro desse contexto, o cultivo do sorgo pode ser uma alternativa técnica e economicamente viável para fornecimento de matéria-prima para silagem na região Amazônica. Entretanto, a região ainda é incipiente em produção e pesquisas nessa cultura.

A implantação de métodos de conservação tem como princípio a manutenção de cobertura vegetal e seus resíduos sobre o solo como, por exemplo, o sistema de plantio direto, tem se destacado como uma das estratégias eficazes para aumentar a sustentabilidade dos sistemas agrícolas nas regiões tropicais e subtropicais (FRANCHINI et al., 2012). O sistema de preparo convencional é comumente utili- zado principalmente por questões de benefícios em curto prazo (BERHE et al., 2013). No entanto, devido a erosão, nesse sistema de cultivo, bem como as elevadas perdas de matéria orgânica, tem sido estimulado a adoção de preparos conservacionistas para manter a cobertura e reduzir a corrosão.

Considerando a escassez de pesquisas sobre produção de sorgo na Amazônia e os feitos decorrentes do manejo e das características físico-química dos solos no estabelecimento da cultura na região emergiram os questionamentos que decorreram no desenvolvimento deste estudo. Nesse viés, o presente trabalho objetivou avaliar a produção e os teores de nutrientes no tecido vegetal de híbridos de sorgo em razão de doses de potássio e sistemas de manejo do solo, cultivados em Latossolo Amarelo, com baixa capacidade produtiva.

\section{MATERIAL E MÉTODOS}

O experimento foi conduzido no período de novembro de 2007 a abril de 2009 em área localizada no Instituto de Ciências Agrárias da Universidade Federal Rural da Amazônia (48 26' 28' W e 01²7'09" S, altitude de 13 metros), localizada no município de Belém (PA). A área possuía um histórico de utilização com jardins clonais de seringueiras e plantio de bananas haviam 15 anos. De acordo com classificação de Köppen o clima predominante na região é o Afi, com temperatura média anual de $26^{\circ}$ $\mathrm{C}$, alta pluviosidade e média de $2.754,4 \mathrm{~mm}$ anuais. As temperaturas máxima, mínima, precipitação pluviométrica e brilho solar durante a condução do experimento estão apresentados na Figura 1.

O solo da área experimental foi classificado como Latossolo Amarelo distrófico (EMBRAPA 2006), do qual foram coletadas amostras nas profundidades de 0 a $0,20 \mathrm{~m}$. A análise química do solo apresentou os seguintes resultados: $\mathrm{pH}\left(\mathrm{H}_{2} \mathrm{O}\right)=4,8$; matéria orgânica (Walkley-Black) =13,2 $\mathrm{g} \mathrm{kg}^{-1} ; \mathrm{P}$ $($ Mehlich-1 $)=66,75 \mathrm{mg} \mathrm{dm}^{-3} ; \mathrm{K}^{+}\left(\mathrm{KCl} 1 \mathrm{~mol} \mathrm{~L}^{-1}\right)=$ $0,24 \mathrm{cmol}_{\mathrm{c}} \mathrm{dm}^{-3} ; \mathrm{Ca}^{2+}\left(\mathrm{KCl} 1 \mathrm{~mol} \mathrm{~L}^{-1}\right)=0,25 \mathrm{cmol}_{\mathrm{c}}$ $\mathrm{dm}^{-3} ; \mathrm{Mg}^{2+}\left(\mathrm{KCl} 1 \mathrm{~mol} \mathrm{~L}^{-1}\right)=2,2 \mathrm{cmol}_{\mathrm{c}} \mathrm{dm}^{-3}$; e H+Al $\left(\mathrm{Ca}(\mathrm{OAc})_{2} 0,5 \mathrm{~mol} \mathrm{~L}^{-1}\right)=4,45 \mathrm{cmol}_{\mathrm{c}} \mathrm{dm}^{-3}$. E com base nos resultados foi calculada a saturação por base $(\mathrm{V} \%)$ e saturação por $\mathrm{Al}(\mathrm{m} \%)=8,7 \%$ e $37,2 \%$, respectivamente (Ribeiro et al. 1999).

A análise granulométrica apresentou 474,5 g $\mathrm{kg}^{-1}$ de areia grossa, 336,5 $\mathrm{g} \mathrm{kg}^{-1}$ de areia fina, $93 \mathrm{~g}$ $\mathrm{kg}^{-1}$ de silte e $96 \mathrm{~g} \mathrm{~kg}^{-1}$ de Argila.

$\mathrm{O}$ delineamento experimental foi em blocos casualizados, arranjados em esquema fatorial 4 x $3 \times$ 2, com quatro repetições. Os fatores foram: quatro doses de potássio $\left(50,100,200\right.$ e $\left.300 \mathrm{~kg} \mathrm{ha}^{-1}\right) \mathrm{na}$ forma de $\mathrm{KCl}$; três híbridos de sorgo (Qualimax, Volumax e AG 2005-E); e dois sistemas de manejo (plantio direto e convencional). As doses de $\mathrm{KCl}$ foram calculadas de acordo com a recomendação de adubação potássica para a cultura do sorgo no Estado 
do Pará (TEIXEIRA; OLIVEIRA; VEIGA, 2007), aplicando-se $100 \mathrm{~kg} \mathrm{KCl} \mathrm{ha}^{-1}$ (equivalente a $60 \mathrm{~kg}$ de $\mathrm{K}_{2} \mathrm{O}$ ha $^{-1}$ ) quando os teores de $\mathrm{K}^{+}$no solo estiver acima de $70 \mathrm{mg} \mathrm{dm}^{-3}$. Desse modo, as doses de po- tássio utilizadas foram 50 ( $1 / 2$ da dose recomendada), 100 (dose recomendada), 200 e $300 \mathrm{~kg} \mathrm{KCl} \mathrm{ha}{ }^{-1}$ (dobro e triplo da dose recomendada).

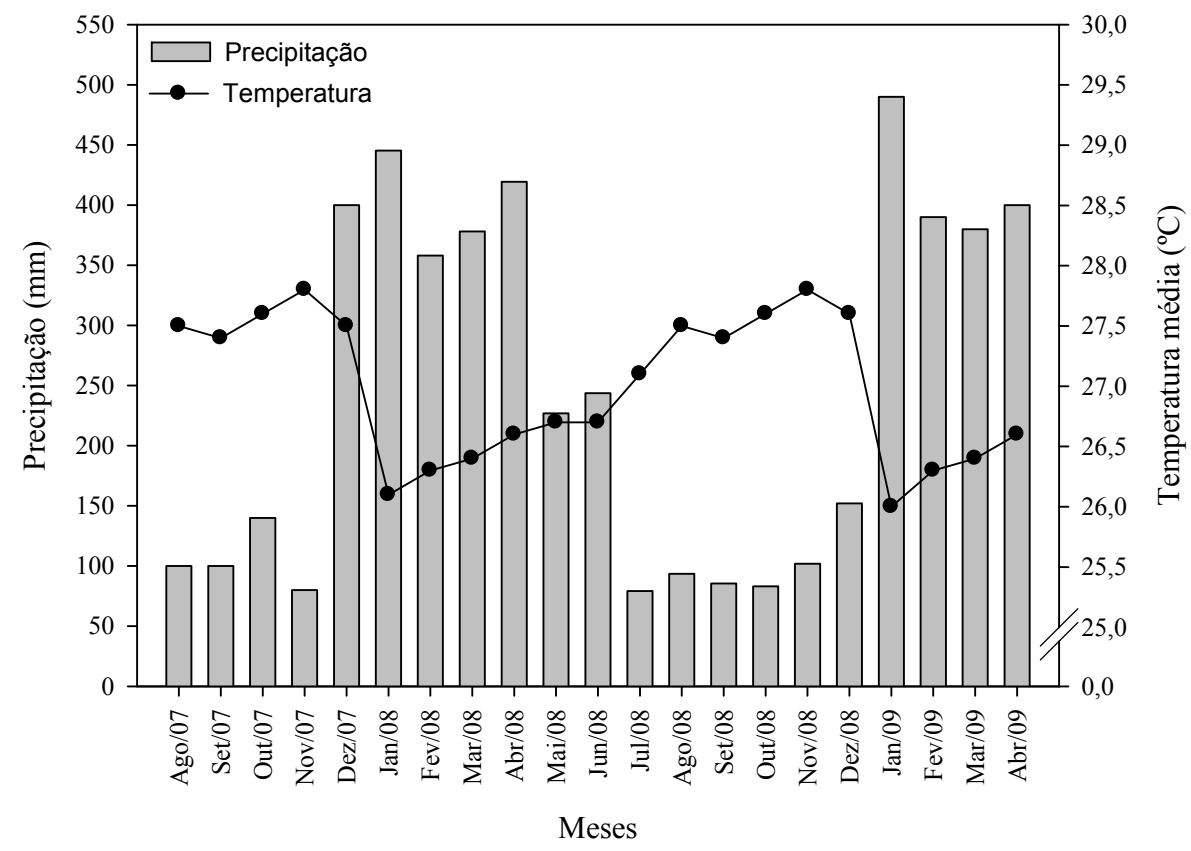

Figura 1. Distribuição da pluviosidade e temperatura do município de Belém durante o período de realização do experimento (agosto/2007 a abril/2009).

Antes da semeadura da cultura do sorgo fora aplicado herbicida dessecante a base de glifosato utilizando volume de aplicação de $3 \mathrm{~L} \mathrm{ha}^{-1}$ para o tratamento com o plantio direto. Na área do plantio convencional o solo foi mobilizado utilizando-se grade aradora. As parcelas constaram de 1,5 m de largura por $4 \mathrm{~m}$ de comprimento com quatro linhas espaçadas em 0,5 $\mathrm{m}$ umas das outras. O semeio foi realizado em sulco utilizando 15 sementes/m linear. Para as avaliações foram consideradas as duas linhas centrais como área útil e as demais servindo apenas como bordadura.

A calagem foi realizada superficialmente na área de plantio direto sobre o resíduo vegetal remanescente e por meio de incorporação na área manejada convencionalmente. A quantidade aplicada foi 2,7 $\mathrm{t} \mathrm{ha}^{-1}$ de calcário dolomítico com PRNT de $90 \%$ objetivando-se elevar a saturação por bases a $60 \%$, seguindo a recomendação de Ribeiro et al. (1999) para a cultura do sorgo.

Foi realizada adubação básica com utilização de $100 \mathrm{~kg} \mathrm{ha}^{-1}$ de $\mathrm{N}$ na forma de sulfato de amônia, $50 \mathrm{~kg} \mathrm{ha}^{-1}$ de P na forma de superfosfato triplo e 30 $\mathrm{kg} \mathrm{ha}^{-1}$ de FTE na linha de plantio, conforme recomendação para cultura do sorgo no estado do Pará (TEIXEIRA; OLIVEIRA; VEIGA, 2007). As doses de potássio foram aplicadas em duas etapas, na qual $50 \%$ da dose recomendada foi aplicada na linha de semeadura por ocasião do plantio e a outra metade trinta dias depois da primeira adubação entre as linhas de semeadura, a uma profundidade aproximada de $3 \mathrm{~cm}$. Nesse mesmo período foi realizada uma adubação de cobertura com $100 \mathrm{~kg} \mathrm{ha}^{-1}$ de $\mathrm{N}$ na forma de ureia.

Quando as plantas estavam no período fenológico de emborrachamento foram coletadas cinco plantas em cada área útil. Posteriormente, o material vegetal foi pesado imediatamente para obtenção da massa verde (RIBAS, 2007). Em seguida, as amostras foram secas em estufa de circulação forçada de ar a $60{ }^{\circ} \mathrm{C}$ até obter peso constante para a obtenção da massa seca. Logo após processou-se a moagem da matéria em moinho tipo Willey e retiradas subamostras as quais foram determinados os teores de macro e micronutrientes.

O material vegetal foi submetido à digestão nítrico-perclórica, sendo determinado no extrato resultante os teores de $\mathrm{N}, \mathrm{P}, \mathrm{K}, \mathrm{Ca}$ e $\mathrm{Mg}$, conforme Malavolta et al. (1997).

Os resultados foram submetidos a análise de variância, comparadas pelo teste de Duncan a 5\%, e quando pertinente estudos de regressão, através do ajuste das equações, de acordo com as doses de $\mathrm{KCl}$ utilizadas. O software estatístico SISVAR 5.3 foi utilizado para a realização das análises estatísticas (FERREIRA, 2011). 


\section{RESULTADOS E DISCUSSÃO}

A matéria seca da parte aérea (MSPA) foi influenciada pelas doses de $\mathrm{KCl}$, sistema de manejo (SM) e híbridos (H) e pela interação dos fatores doses $\mathrm{KCl}$ x SM. Os resultados da análise de variância do tecido vegetal do sorgo mostraram efeito isolado das doses de potássio, aplicado na forma de $\mathrm{KCl}$, para o $\mathrm{K}, \mathrm{Ca}$ e $\mathrm{Mg}$ e dos sistemas de manejo para os nutrientes $\mathrm{N}, \mathrm{P}, \mathrm{K}, \mathrm{Ca}$ e $\mathrm{Mg}$ e de híbridos para o $\mathrm{Mg}$. Foram observadas ainda interações significativas entre as doses de $\mathrm{KCl}$ x SM para os nutrientes $\mathrm{Ca}$ e $\mathrm{Mg}$ e doses de $\mathrm{KCl} \times \mathrm{H}$ e $\mathrm{SM} \times \mathrm{H}$ para o $\mathrm{Mg}$ (Tabela 1).

Tabela 1. Valores de quadrados médios de matéria seca da parte aérea (MSPA) e teores de N, P, K, Ca e Mg no tecido foliar em função de doses de $\mathrm{KCl}$ em híbridos de Sorghum bicolor cultivado em sistema de plantio convencional e plantio direto.

\begin{tabular}{lccccccr}
\hline Fonte de Variação & GL & MSPA & N & P & K & Ca & Mg \\
\hline Doses de KCl (D) & 3 & $6849025,82^{*}$ & 1,53 & 0,25 & $74,11^{* *}$ & $0,80^{* *}$ & $19,62^{* *}$ \\
Sistema de Manejo (S.M) & 1 & $45040531,14^{* *}$ & $306,05^{* *}$ & $51,74^{* *}$ & $188,52^{* *}$ & $6,55^{* *}$ & $539,03^{* *}$ \\
Híbridos (H) & 2 & $16435047,06^{* *}$ & 1,41 & 0,07 & 1,06 & 0,00 & $9,65^{* *}$ \\
D x SM & 3 & $8121800,48^{*}$ & 1,30 & 0,07 & 2,53 & 0,37 & $11,88^{* *}$ \\
D x H & 6 & 1501031.50 & 2,47 & 0,13 & 1,28 & 0,09 & $3,91^{*}$ \\
SM x H & 2 & 2200571,12 & 0,14 & 0,21 & 0,04 & 0,04 & $14,27^{* *}$ \\
Erro & 77 & 2015514,20 & 1,13 & 0,12 & 1,82 & 0,07 & 1,55 \\
C.V (\%) & - & - & 18,26 & 27,71 & 22,68 & 15,97 & 28,25 \\
\hline
\end{tabular}

$* \mathrm{e}^{* *}=$ significante a $p<0,05$ e $p<0,01$.

Os híbridos Volumax e Qualimax apresentaram produtividade de MSPA superior ao AG 2005-E. A produção do híbrido AG 2005-E foi 13\% inferior à produtividade do Volumax e $7 \%$ a do híbrido Qualimax (Figura 2).

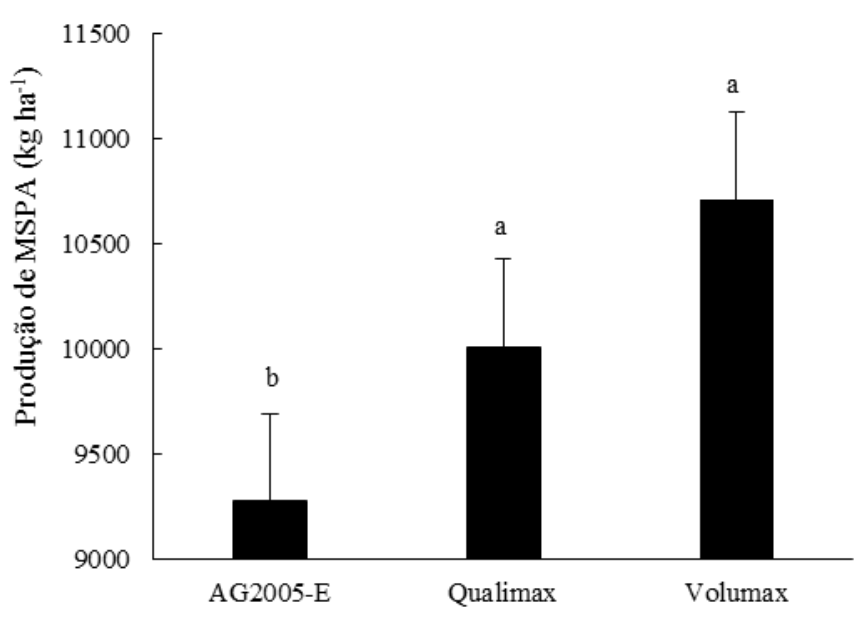

Figura 2. Produtividade de matéria seca da parte aérea (MSPA) nos híbridos de $S$. bicolor. Letras diferentes nas colunas diferem a $p<0,05$. As barras representam o erro padrão.

Estudando híbridos forrageiros, duplo propósito e graníferos, Von Pinho et al. (2006) observaram maior produção por área cultivada para o sorgo $\mathrm{Vo}_{\mathrm{o}}$ lumax quando comparado a outros híbridos, tendo atribuído essa superioridade ao maior porte do mesmo. Em estudos realizados por Skonieski et al. (2010) com sorgo de duplo propósito em Podzólico Vermelho Amarelo foram encontrados percentuais de MSPA de 32,23\% para o híbrido Volumax, semelhantes aos encontrados no experimento, que apresentou $30,38 \%$. As produções de matéria seca obtidas para o Volumax e AG 2005 foram superiores às observadas em alguns trabalhos, quais sejam, $6.843 \mathrm{e}$
$9.475 \mathrm{~kg} \mathrm{ha}^{-1}$ (AVELINO et al., 2011) e 9.464 e $8.408 \mathrm{~kg} \mathrm{ha}^{-1}$ (GOMES et al., 2008) em Latossolo Vermelho.

As doses de $\mathrm{KCl}$ influenciaram significativamente a produção de MSPA nos dois sistemas de uso do solo, ajustando-se ao modelo quadrático de regressão. O rendimento máximo estimado de MSPA para o plantio direto (PD) foi de $10.835 \mathrm{~kg} \mathrm{ha}^{-1}$, obtido com a dose de $152 \mathrm{~kg} \mathrm{ha}^{-1}$ de $\mathrm{K}$, enquanto que para o plantio convencional (PC) a produção foi de $10.310 \mathrm{~kg} \mathrm{ha}^{-1}$ na dose de $213 \mathrm{~kg} \mathrm{ha}^{-1}$ de $\mathrm{K}$ (Figura 3). 


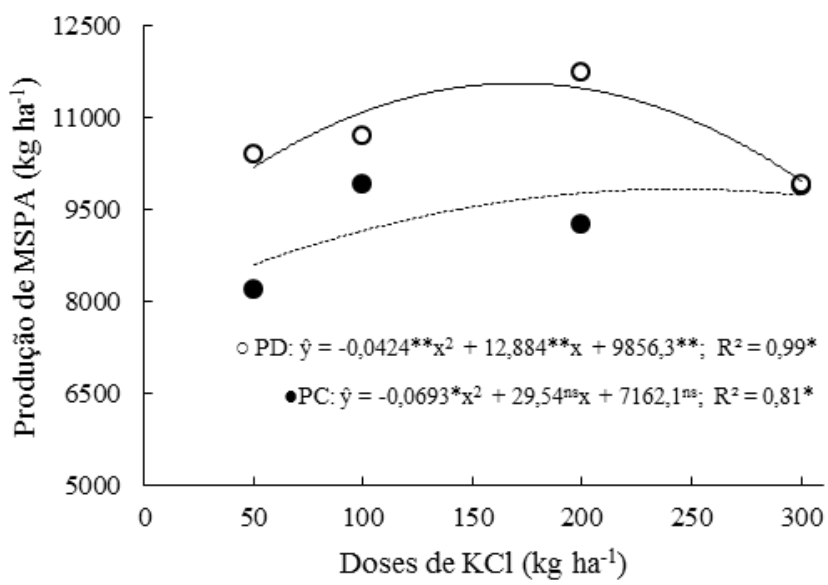

Figura 3. Matéria seca da parte aérea (MSPA) de S. bicolor em função de doses de $\mathrm{KCl}$ nos sistemas de plantio convencional (PC) e direto (PD). *significativo $p<0,05 \mathrm{e}^{* *}$ significativo $p<0,01$.

As maiores produções obtidas no plantio direto, com menores doses de $\mathrm{KCl}$, quando comparado ao plantio convencional, podem estar relacionados a maior proteção e capacidade do solo não revolvido acumular nutrientes, principalmente potássio, na camada superficial (CRUSCIOL et al., 2005). Crusciol et al. (2011), em Nitossolo Vermelho do estado de São Paulo, obtiveram 15,65 t de matéria seca da parte aérea de híbrido P8118 quando cultivado no sistema de plantio direto. A maior produção obtida pelos autores ora citados pode estar relacionada ao híbrido e as condições edafoclimáticas que favoreceram a produção. Quando cultivado em sistema de plantio convencional, a incorporação dos resíduos no sistema convencional acelera a decomposição, aumentando as perdas de nutrientes. Segundo Alijani et al. (2012), a remoção de resíduos de forma completa deve ser evitada, principalmente em solos com baixo teor de argila decorrente da redução dos teores de matéria orgânica e erosão.

Estudos com a adubação potássica de forma isolada são escassos e mesmo assim as respostas ao $\mathrm{K}$ têm sido variadas. Em trabalho avaliando o rendimento acumulado de grãos de soja, milho e sorgo cultivado em Argissolo Vermelho Distrófico arênico, Brunetto et al. (2005) constataram aumento com a adubação potássica, mesmo o solo apresentando 1,5 $\mathrm{mmol}_{\mathrm{c}} \mathrm{dm}^{-3}$ de K. Em Jaboticabal (SP), Simili et al. (2008) observaram que a adubação potássica não influenciou a matéria seca, a porcentagem de colmos e folhas do sorgo-Sudão cultivado em Latossolo Vermelho Distrófico, textura média. Diferentemente do solo deste estudo, que apresentou 0,24 $\mathrm{mmol}_{\mathrm{c}} \mathrm{dm}^{-3}$ de $\mathrm{K}$, na camada de $0-0,2 \mathrm{~m}$, o solo em que foi cultivado o sorgo-Sudão continha $0,42 \mathrm{mmol}_{\mathrm{c}} \mathrm{dm}^{-3} \mathrm{de} \mathrm{K}$, fato que pode ter sido determinante para a falta de resposta a adubação potássica. De acordo com trabalhos realizados por Andreotti et al. (2000) em híbridos de milho Zêneca 8392, o K proporcionou aumento na produção de matéria seca até teores de 1,5 $\mathrm{mmol}_{\mathrm{c}} \mathrm{dm}^{-3}$ de $\mathrm{K}$ no solo. A cultura do milho tam- bém não respondeu a adubação potássica, quando cultivado em área irrigada de um Latossolo Vermelho Distrófico típico da região de Cruz Alta, RS com 5,1 e 4,3 $\mathrm{mmol} \mathrm{dm}^{-3}$ de $\mathrm{K}$, no primeiro e segundo anos de cultivos, respectivamente (PAVINATO et al., 2008).

Para os teores de nutrientes da parte aérea foram encontradas diferenças significativas de acordo com a forma de plantio. Os teores de $\mathrm{N}$ e $\mathrm{P}$, independente do híbrido estudado, foram maiores quando cultivado no plantio direto, apresentando aumento de 89 e $274 \%$, respectivamente, quando comparado ao plantio convencional (Figura 4.A).

$\mathrm{O}$ teor de fósforo $(\mathrm{P})$ da matéria seca da parte aérea do sorgo, no plantio direto, apresentou valor médio de $1,98 \mathrm{~g} \mathrm{~kg}^{-1}$, porém o plantio convencional apresentou valor de $0,51 \mathrm{~g} \mathrm{~kg}^{-1}$ (Figura 4B). O nutriente que apresentou os maiores valores na MSPA foi o potássio $(\mathrm{K})$, com valor de $7,35 \mathrm{~g} \mathrm{~kg}^{-1}$ observado para o plantio direto e $4,57 \mathrm{~g} \mathrm{~kg}^{-1}$ para o plantio convencional, independente dos híbridos estudados (Figura 4C).

Os teores de $\mathrm{N}$ verificados na matéria seca da parte aérea se encontram abaixo dos considerados ideais a cultura do sorgo, como demonstrados por Martinez et al. (1999). Isso pode estar relacionado a grande exigência desse elemento pela espécie produtora de grãos. Em sistema de plantio direto, além de ocorrer imobilização por microrganismos do solo no processo de decomposição da cobertura morta há também a imobilização do nutriente pelo capim (SEVERINO et al., 2006). A manutenção de resíduos vegetais em superfície e ausência de revolvimento do solo promove maior retenção de nutrientes, como o $\mathrm{K}$, cálcio $(\mathrm{Ca})$ e magnésio $(\mathrm{Mg})$, e pode atuar como reservatório de nitrogênio $(\mathrm{N})$, fósforo $(\mathrm{P})$ e enxofre (S), capaz de suprir parte das necessidades da cultura durante seu ciclo (CALEGARI, 2004). Segundo Meki et al. (2013), a remoção a longo prazo da palhada sobre o solo resultou em rendimentos reduzidos de biomassa total ao longo do tempo devido ao esgota- 
mento de nutrientes que poderia ser atribuído à mineralização reduzida, às perdas e talvez imobilização do nitrogênio $(\mathrm{N})$.

Os teores de fósforo $(\mathrm{P})$ da matéria seca da parte aérea do sorgo, no plantio direto, se encontram acima dos valores considerados adequados. No entanto, no plantio convencional, esses valores estão bem próximos aos considerados ideais para a cultura (MARTINEZ et al., 1999). Os elevados teores encontrados no solo podem ter influenciados esses teores elevados de fósforo $(\mathrm{P})$ na massa seca da parte aérea do sorgo.
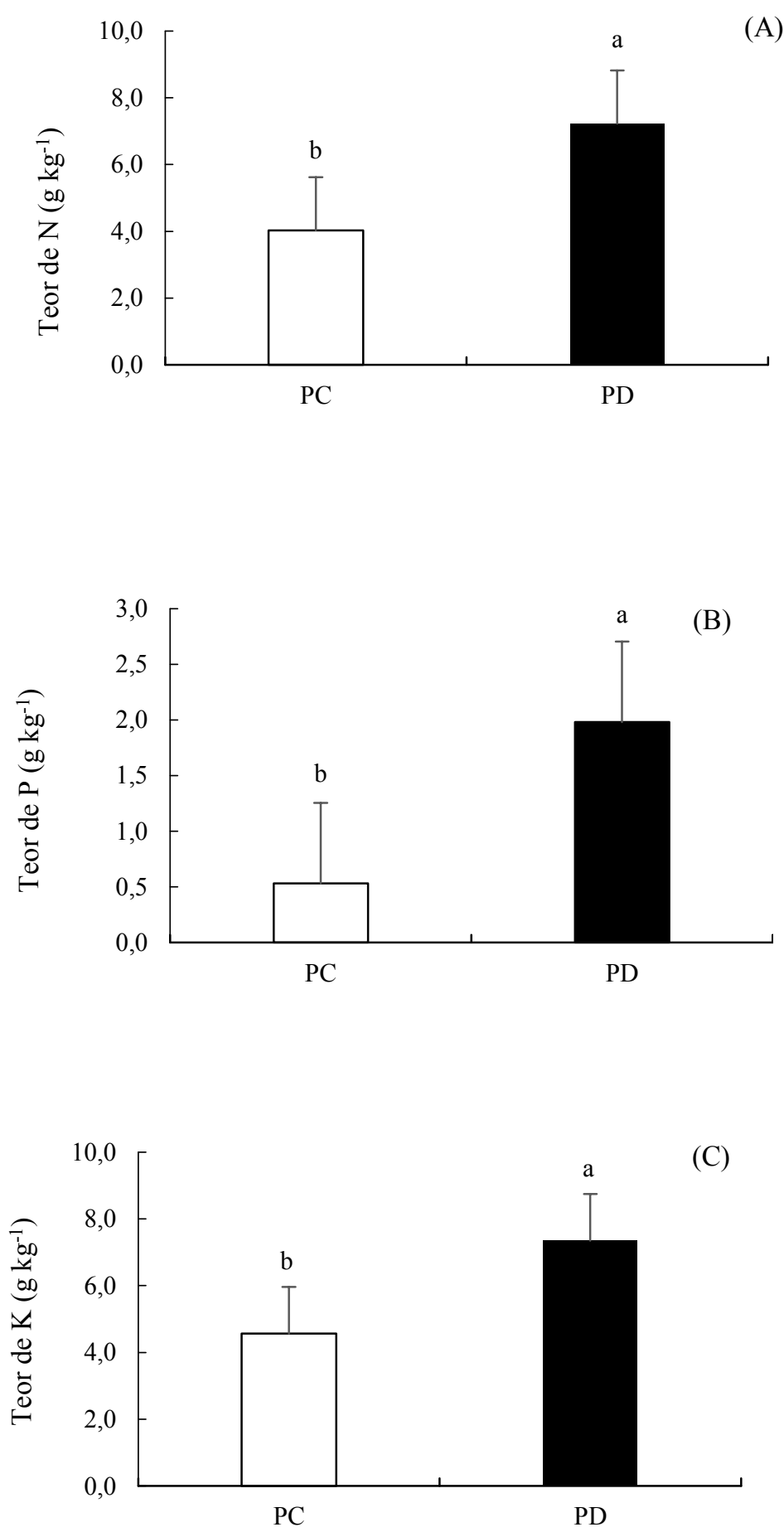

Figura 4. Teores de nitrogênio (fig. A), fósforo (fig. B) e potássio (fig. C) na matéria seca da parte aérea de $S$. bicolor nos sistemas de plantio convencional (PC) e direto (PD). Letras diferentes nas colunas em cada sistema de manejo diferem a $p<0,05$. As barras representam o erro padrão. 
Os maiores teores de K na MSPA (Figura 4a) foram observados no plantio direto $\left(7,35 \mathrm{~g} \mathrm{~kg}^{-1}\right)$ comparado ao plantio convencional $\left(4,55 \mathrm{~g} \mathrm{~kg}^{-1}\right)$, independente dos híbridos estudados. Esses teores se encontram abaixo dos valores de referência para a cultura demonstrados por Martinez et al. (1999). A elevada quantidade de chuvas no período pode ter contribuído para uma maior lixiviação do elemento. Além disso, a cultura do sorgo granífero apresenta alta demanda de $\mathrm{K}$, que é alocado preferencialmente nos colmos, o que diminui a translocação para as folhas.

As doses de potássio proporcionaram aumento linear significativo nos teores de K no tecido vegetal da MSPA do sorgo (Figura 5). Aumentos lineares nos teores de $\mathrm{K}$, em função das doses do nutrientes, foram obtidos por Valderrama et al. (2011) em milho irrigado sob plantio direto.

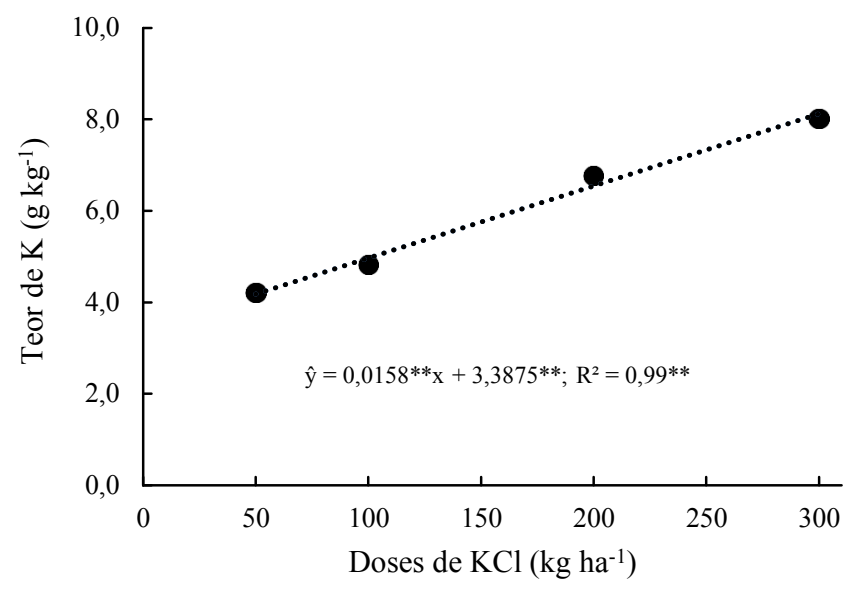

Figura 5. Teor de $\mathrm{K}$ na matéria seca da parte aérea de $S$. bicolor em função das doses de $\mathrm{KCl} .{ }^{* *}$ significativo $p<0,01$.

A interação entre as doses de $\mathrm{KCl}$ e o sistema de plantio direto afetaram significativamente os teo- res de $\mathrm{Ca}$ no plantio direto, com as médias ajustandose ao modelo quadrático de regressão (Figura 6).

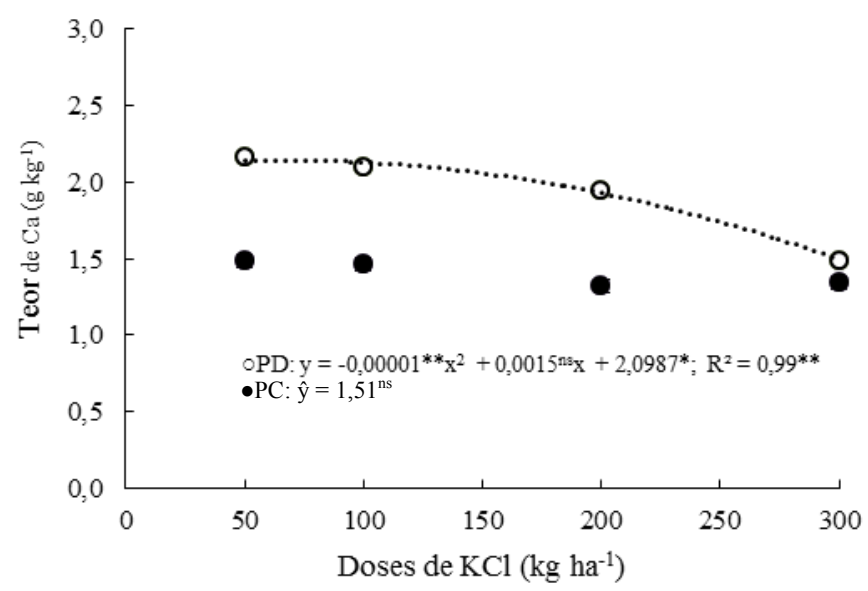

Figura 6. Teores de Ca na matéria seca da parte aérea de $S$. bicolor em função de doses de $\mathrm{KCl}$ nos sistemas de plantio convencional (PC) e direto (PD). *significativo a $p<0,05$ e ** significativo $p<0,01$ e ns $=$ não significativo.

Foi observado decréscimo nos teores de $\mathrm{Ca}$ na medida em que se aumentaram as doses de $\mathrm{KCl}$. Segundo Mengel e Kirkby (2001), a soma total de cátions em uma planta é pouco variável com o incremento no suprimento de um cátion, pois geralmente ocorre redução na proporção de outros cátions presentes. Esse fenômeno de um íon em excesso reduzir a absorção de outros é chamado de antago- nismo, fato que pode justificar o ocorrido no presente trabalho.

Os teores de $\mathrm{Mg}$ foram influenciados significativamente pela interação entre os fatores estudados. Na interação entre doses e sistemas o efeito foi significativo apenas para o plantio direto, com equação de regressão ajustando-se ao modelo linear decrescente (Figura 7). 


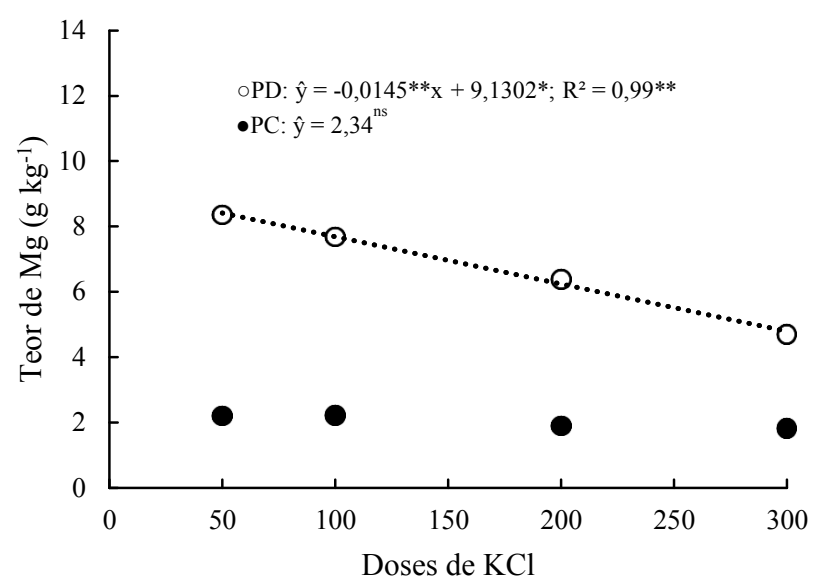

Figura 7. Teores de Mg na matéria seca da parte aérea de S. bicolor em função de doses de $\mathrm{KCl}$ nos sistemas de plantio convencional (PC) e direto (PD). *significativo a $p<0,05$ e $* * p<0,01$ e ns $=$ não significativo.

$\mathrm{O}$ teor de $\mathrm{Mg}$ foram influenciados significativamente pela interação entre doses de $\mathrm{KCl}$ e híbridos ajustando-se ao modelo linear decrescente (Figura 8).

Os teores de Mg da matéria seca da parte aérea entre híbridos não apresentaram diferenças signi- ficativas no plantio convencional, diferentemente do plantio direto, que foi observado efeito significativo para esse fator, sendo AG2005-E o híbrido que apresentou os maiores teores de Mg (Figura 9).

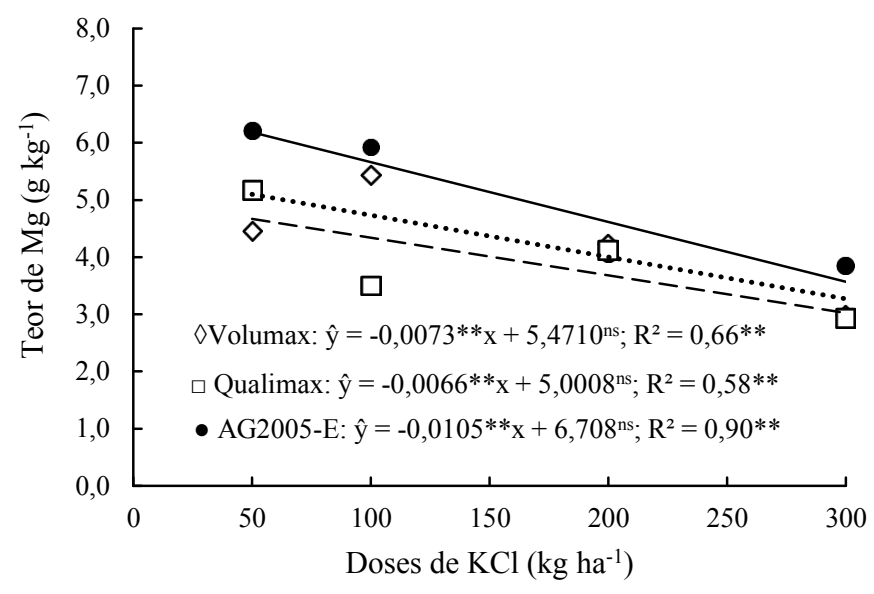

Figura 8. Teores de Mg na matéria seca da parte aérea de híbridos de $S$. bicolor em função de doses de KCl. **significativo $p<0,01$.

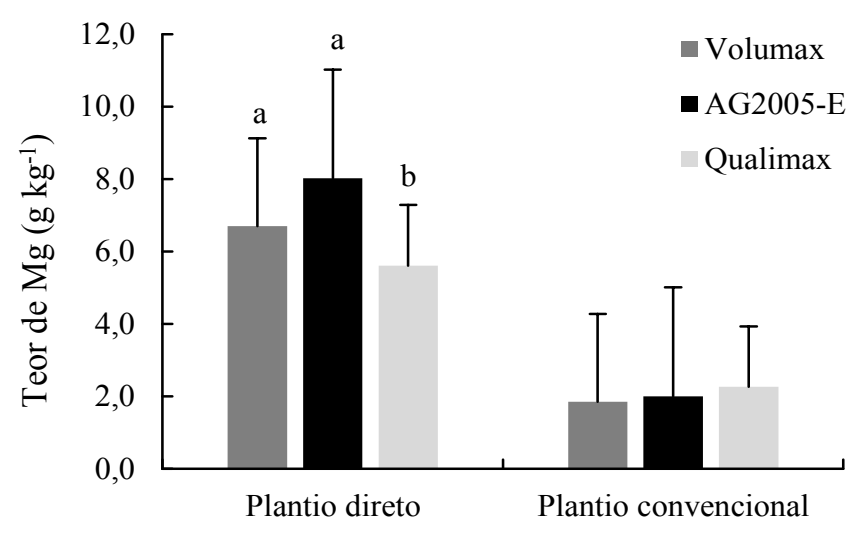

Figura 9. Teores de Mg na matéria seca da parte aérea de híbridos de $S$. bicolor nos sistemas de plantio convencional (PC) e direto (PD). Letras diferentes nas colunas em cada sistema de manejo diferem a $p<0,05$. As barras representam o erro padrão. 
As plantas de sorgo cultivadas no sistema de plantio direto apresentaram os maiores teores de $\mathrm{Mg}$. Nesse sistema há uma maior adsorção de $\mathrm{Mg}$ nos colóídes do solo, quando comparado ao plantio convencional. De acordo com Epstein e Bloom (2006), como o magnésio apresenta menor adsorção aos colóides do solo do que outros nutrientes, como o cálcio, por exemplo, além de apresentar raio iônico hidratado maior do que o do cálcio sua lixiviação tende a ser mais intensa no sistema de plantio convencional.

Com o aumento das doses de $\mathrm{KCl}$ há um decréscimo no teor de $\mathrm{Mg}$, o que se atribui, assim como ao $\mathrm{Ca}$, ao efeito antagônico entre os cátions. $\mathrm{O}$ maior teor de $\mathrm{Mg}$ encontrado no híbrido AG2005-E pode estar ligado ao fator genético que predispõe a planta a apresentar bom desenvolvimento em concentrações menores de $\mathrm{K}$ durante seu ciclo quando comparados aos demais híbridos (TOMICH et al., 2004). Analisando os teores de Mg na MSPA do milho submetido a adubação orgânica e compactação do solo, Rodrigues et al. (2009) relataram que o aumento no teor de potássio proporcionou a diminuição do teor de magnésio nas plantas de milho, devendo-se atentar aos efeitos antagônicos entre esses cátions, principalmente quando o suprimento de potássio for elevado.

\section{CONCLUSÕES}

Os híbridos volumax e qualimax cultivados no sistema de plantio direto apresentaram maior produção de matéria seca da parte aérea. Os híbridos de sorgo cultivados no sistema de plantio direto apresentaram os maiores teores de N, P, K, Ca e Mg nos tecidos foliares. A adubação potássica no sistema de plantio direto aumentou a produção de matéria seca da parte aérea de sorgo cultivado em Latossolo de baixa capacidade produtiva na Amazônia e reduziu em $40 \%$ a aplicação de $\mathrm{KCl}$ em relação ao plantio convencional.

\section{REFERÊNCIAS}

ALIJANI, K.; BAHRANI, M. J.; KAZEMEINI, S. A.. Short-term responses of soil and wheat yield to tillage, corn residue management and nitrogen fertilization. Soil and Tillage Research, Amsterdam, v. 124 , n. 1 , p. $78-82,2012$.

ANDREOTTI, M. et al. Produção de matéria seca e absorção de nutrientes pelo milho em razão da saturação por bases e da adubação potássica. Pesquisa Agropecuária Brasileira, Brasília, v. 35, n. 12, p. 2437-2446, 2000.

AVELINO, P. M. et al. Características agronômicas e estruturais de híbridos de sorgo em função de dife- rentes densidades de plantio. Revista Ciência Agronômica, Fortaleza, v. 42, n. 2, p. 534-541, 2011.

BERHE, F. T. et al. The effect of tillage practices on grain yield and water use efficiency. Catena, Amsterdam, v. 100, n. 1, p. 128-138, 2013.

BRUNETTO, G. et al. Nível crítico e resposta das culturas ao potássio em um Argissolo sob sistema plantio direto. Revista Brasileira de Ciência do Solo, Viçosa, v. 29, n. 4, p. 565-571. 2005.

CALEGARI, A. Alternativa de rotação de culturas para plantio direto. Revista Plantio Direto, Passo Fundo, v. 80, n. 1, p. 62-70, 2004.

CRUSCIOL, C. A. C. et al. Persistência de palhada e liberação de nutrientes do nabo forrageiro no plantio direto. Pesquisa Agropecuária Brasileira, Brasília, v. 40, n. 2, p. 161-168, 2005.

CRUSCIOL, C. A. C. et al. Nutrição e produtividade de híbridos de sorgo granífero de ciclos contrastantes consorciados com capim $\square$ marandu. Pesquisa Agropecuária Brasileira, Brasília, v. 46, n. 10, p. 12341240, 2011.

DE MELLO, A. H. et al. Caracterização Química do Solo em Áreas de Floresta, Plantações de Arroz, Milho e Mandioca no Projeto de Assentamento Nova Vida - Marabá-PA. Revista Brasileira de Agroecologia, Cruz Alta, v. 4, n. 2, p. 535-538, 2009.

EMBRAPA. Sistema brasileiro de classificação de solos. 2. ed. Rio de Janeiro, RJ: EMBRAPA - CNPS, 2006. $306 \mathrm{p}$

EPSTEIN, E.; BLOOM, A. J. Nutrição mineral de plantas: princípios e perspectivas. Londrina, PR: PLANTA, 2006. $403 \mathrm{p}$.

FERNANDES, F. E. P. et al. Ensilagem de sorgo forrageiro com adição de uréia em dois períodos de armazenamento. Revista Brasileira de Zootecnia, Viçosa, v. 38, n. 11, p. 2111-2115, 2009.

FERREIRA, D. F. Sisvar: A computer statistic alanalysis system. Ciência e Agrotecnologia, Lavras, v. 35 , n. 6 , p. 1039-1042, 2011.

FRANCHINI, J. C. et al. Evolution of crop yields in different tillage and cropping systems over two decades in southern Brazil. Field Crops Research, Amsterdan, v. 137, n. 1, p. 178-185, 2012.

GOMES, S. O. et al. Comportamento agronômico e composição químico-bromatológico de cultivares de sorgo forrageiro no Estado do Ceará. Revista Ciência Agronômica, Fortaleza, v. 37, n. 2, p. 221-227, 2008. 
MALAVOLTA, E. et al. Avaliação do estado nutricional das plantas: princípios e aplicações. 2. ed. Piracicaba, SP: POTAFOS, 1997. 319 p.

MARTINEZ, H. E. P. et al. Diagnose foliar. In: RIBEIRO, A. C. et al. (Ed.). Recomendações para o uso de corretivos e fertilizantes em Minas Gerais. Viçosa: UFV, 1999. $5^{\text {a }}$ aproximação, cap. 17, p. 143168.

MEKI, M. N. et al. Energy sorghum biomass harvest thresholds and tillage effects on soil organic carbon and bulk density. Industrial Crops and Products, Amsterdan, v. 43, n. 1, p. 172-182, 2013.

MENGEL, K.; KIRKBY, E. A. Principles of plant nutrition. 5. ed. Dordrechth, ZH: Kluwer Academic Publishers, 2001. 849 p.

PAVINATO, P. S. et al. Nitrogênio e potássio em milho irrigado: análise técnica e econômica da fertilização. Ciência Rural, Santa Maria, v. 38, n. 2, p. 358-364, 2008.

RIBAS, P. M. Importância econômica, Cultivo do Sorgo, Embrapa Milho e Sorgo, Sistemas de Produção 2, Versão Eletrônica, set. 2007. Disponível em: http: <//www.cnpms.embrapa.br/publicacoes/sorgo/ importancia.htm>. Acesso em: 12 out. 2012.

RIBEIRO, A. C.; GUIMARÃES, P. T. G.; ALVAREZ V, V. H. Recomendações para o uso de corretivos e fertilizantes em Minas Gerais. $5^{\text {a }}$ aproximação. Viçosa, MG: CFSEMG, 1999. 359 p.

RODRIGUES, P. N. F. et al. Crescimento e composição mineral do milho em função da compactação do solo e da aplicação de composto orgânico. Revista Brasileira de Engenharia Agrícola e Ambiental, Campina Grande, v. 13, n. 1, p. 94-99, 2009.

SEVERINO, F. J. et al. Interferências mútuas entre a cultura do milho, espécies forrageiras e plantas daninhas em um sistema de consórcio. II - Implicações sobre as espécies forrageiras. Planta daninha, Viçosa, v. 24, n. 1, p. 45-52, 2006

SILVA, R. et al. Avaliação de diferentes genótipos de sorgo para forragem e silagem. Revista Brasileira de Milho e Sorgo, Sete Lagoas, v. 11, n. 3, p. 225 $-233,2012$.

SIMILI, F. F. et al. Resposta do híbrido de sorgosudão à adubação nitrogenada e potássica: composição química e digestibilidade in vitro da matéria orgânica. Ciência agrotecnologia, Lavras, v. 32, n. 2, p. 474-480, 2008.

SKONIESKI, F. R. S. et al. Produção, caracterização nutricional e fermentativa de silagem de sorgo forrageiro e sorgo duplo propósito. Acta Scientiarum. Animal sciences, Maringá, v. 32, n. 1, p. 27-32, 2010 .

TEIXEIRA, L. B.; OLIVEIRA, R. F.; VEIGA, J. B. et al. Recomendação de Adubação e Calagem para pastagens e gramados. In: CRAVO, M. S. et al. (Ed.). Recomendações de adubação e calagem para o Estado do Pará. Belém: Embrapa Amazônia Oriental, 2007. p. 257-262.

TERRA, T. G. R. et al. Desenvolvimento e produtividade de sorgo em função de diferentes densidades de plantas. Bioscience Journal, Uberlândia, v. 26, n. 2, p. 208-215, 2010.

TOMICH, T. R. et al. Potencial forrageiro de híbridos de sorgo com capim-sudão. Arquivo Brasileiro de Medicina Veterinária e Zootecnia, Belo Horizonte, v. 56, n. 2, p. 258-263, 2004.

VALDERRAMA, M. et al. Fontes e doses de NPK em milho irrigado sob plantio direto. Pesquisa Agropecuária Tropical, Goiânia, v. 41, n. 2, p. $254-$ 263,2011

VON PINHO, R. G. et al. Influência da altura de corte das plantas nas características agronômicas e valor nutritivo das silagens de milho e de diferentes tipos de sorgo. Revista Brasileira de Milho e Sorgo, Sete Lagoas, v. 5, n. 2, p. 266-279, 2006 